Vol. 23, No. 1, pp. 89 100, 2020.

\title{
A Brief Review of Enhancing Incipient Piezostrains: Approach by Ceramic/Ceramic Composites
}

\author{
Hyoung-Su Han ${ }^{1 \dagger}$, Trang An Duong ${ }^{1}$, Chang Won Ahn' ${ }^{2}$, Wook Jo ${ }^{3}$, Jae-Shin Lee ${ }^{1}$ \\ ${ }^{1}$ School of Materials Science and Engineering, University of Ulsan, Ulsan 44610, Korea \\ ${ }^{2}$ Department of Physics \& EHSRC, University of Ulsan, Ulsan 44610, Korea \\ ${ }^{3}$ Materials Science and Engineering, Ulsan National Institute of Science and Technology, Ulsan 44919, Korea
}

\section{비스무스계 무연 압전세라믹스의 저전계 변형특성 향상을 위한 세라믹/세라믹 복합소재 기술}

\author{
한형수 ${ }^{\dagger}$, 즈엉 짱 안, 안창원 ${ }^{2}$, 조욱 ${ }^{3}$, 이재신 ${ }^{1}$ \\ 1울산대학교 첨단소재공학부, ${ }^{2}$ 울산대학교 물리학과 \& EHSRC, ${ }^{3}$ 울산과학기술원 신소재공학부
}

(Received Febrary 25, 2020; Revised March 19, 2020; Accepted March 20, 2020)

\begin{abstract}
초록
Abnormally large electromechanical strain properties have been reported in bismuth-based piezoelectric ceramics, which cast a promise for replacing the market-dominating PZT-based piezoelectric ceramics in actuator applications. In spite of these large strains in bismuth-based piezoelectric ceramics, there still remains a critical issue for its safe transfer to practical applications, representatively, a relatively high operating field required to obtain the large strain properties. To overcome the challenge, much attention has been paid to so-called $0-3$ (or 3-0) type ceramic/ceramic composite approach to better tailoring the strain properties of bismuth-based piezoelectric ceramics. The approach turns out to be highly effective, leading to a drastic decrease in the operating electric field for these materials. Besides, both extensive and intensive search for the related mechanism revealed that the reduction in the operating electric field is largely due to the contribution from polarization coupling or strain coupling model between two different ceramics. This article reviews the status of the art in the development of novel ceramic/ceramic composites to make large incipient piezostrains in bismuth-based lead-free piezoelectric ceramics practical.
\end{abstract}

Keywords: lead-free piezocermics; electromechanical strain; composites

${ }^{\dagger}$ Corresponding Author: Hyoung-Su Han

E-mail: hsejs@ulsan.ac.kr 


\section{특 집 ㅁㅃ 한형수, 즈엉 짱 안, 안창원, 조욱, 이재신}

\section{1. 서론}

압전현상은 기계적 응력을 압전 세라믹스에 인가하면 응력에 비례하는 분극이 발생되고 역으로 전계를 인가 하면 이에 비례하는 기계적 변형이 발생되는 현상으로 액추에이터, 센서, 초음파 모터 등 다양한 분야에 활용 되고 있다. ${ }^{1,2)}$ 특히, 압전 현상 기반 전계유기(electricfield-induced) 변형특성은 기계적 변형을 활용한 액 추에이터와 같은 소자에 가장 중요한 특성 중에 하나이 다. 지금까지 상업적으로 실용 되고있는 압전소재는 대 부분 뛰어난 압전특성을 나타내는 납(lead; $\mathrm{Pb})$ 을 함유 한 $\mathrm{Pb}(\mathrm{Zr}, \mathrm{Ti}) \mathrm{O}_{3}(\mathrm{PZT})$ 계 세라믹스지만, 납은 인체와 환 경적으로 문제를 발생시킬 수 있어서 유럽연합을 중심 으로 전자장비에 납과 같은 유해물질의 사용을 규제하 고 있다. ${ }^{3,4)}$ 아직까지는 PZT계 압전세라믹스를 대체할 뚜렷한 무연 압전세라믹스가 개발되지 않아 예외 조항 으로 분류되고 있는 상황이지만 일시적인 방침일 뿐 향 후 개발된 물질의 성능을 고려하여 언제든지 규제에 포 함될 예정이다. 이러한 배경으로 무연 압전(lead-free) 소재 개발에 관한 연구가 활발하게 진행되어 왔다. 실 제 무연 압전소재에 대한 연구는 1976년에 Okazaki 교 수를 중심으로 일본에서 가장 먼저 시작되었다고 알려 져 있으며, ${ }^{5,6)}$ 그 결과 1991년 $\left(\mathrm{Bi}_{1 / 2} \mathrm{Na}_{1 / 2}\right) \mathrm{TiO}_{3}-\mathrm{BaTiO}_{3}$ (BNT-BT)계, ${ }^{7)}$ 1999년 $\left(\mathrm{Bi}_{1 / 2} \mathrm{Na}_{1 / 2}\right) \mathrm{TiO}_{3}-\left(\mathrm{Bi}_{1 / 2} \mathrm{~K}_{1 / 2}\right) \mathrm{TiO}_{3}$
$(\mathrm{BNT}-\mathrm{BKT})$ 계 $)^{8)}$ 개발로 이어졌다. 나아가 2000년대에 는 레조네이터 (Resonator)용으로 상용화가 가능한 비 스무스 층상 구조(Bi layered structure)의 강유전 재료 개발 및 2004년 PZT에 버금가는 성능을 가진 결정 배 향된 $(\mathrm{K}, \mathrm{Na}) \mathrm{NbO}_{3}(\mathrm{KNN})$ 계 세라믹스 ${ }^{9}$ 가 개발되었다. ${ }^{6}$ 이 후, 그림 1 과 같이 전 세계적으로 지난 20 여 년간 무 연 압전소재를 개발에 노력한 결과 대표적인 무연 압전 세라믹스는 $\mathrm{BNT}$ 계, $\mathrm{KNN}$ 계, $\mathrm{BiFeO}_{3}-\mathrm{BaTiO}_{3}(\mathrm{BF}-$ $\mathrm{BT}$ )계 ${ }^{10)}$ 및 $\mathrm{BaTiO}_{3}(\mathrm{BT})$ 기반 $(\mathrm{Ba}, \mathrm{Ca}) \mathrm{TiO}_{3}-\mathrm{Ba}(\mathrm{Zr}, \mathrm{Ti})$ $\mathrm{O}_{3}(\mathrm{BCT}-\mathrm{BZT})$ 계 ${ }^{11)}$ 등으로 대략 네 가지 계로 구분할 수 있다.

비록 이 소재들 중 그 어느 소재도 기존의 $\mathrm{PZT}$ 계 의 뛰어난 특성에는 미치지 못하지만, 일부 특화된 응 용분야에 있어서는 $\mathrm{PZT}$ 계를 대체할 충분한 가능성을 보였다. 실제 2007년 독일 Technische Universität Darmstadt의 Zhang 등에 의해 개발된 BNT-BT$\mathrm{KNN}$ 삼성분계 무연 압전세라믹스르는 그림 2 와 같이 $\mathrm{PZT}$ 계 보다 뛰어난 성능의 전계인가유기 변형특성을 가진다고 보고되었다. 이러한 성능은 액추에이터 분야 에서 PZT계를 대체할 가능성을 보여 그림 1에 명시된 바와 같이 BNT계 무연 압전세라믹스에 대한 연구를 더 욱 촉진시켰다.

이 후 2012년 조욱 교수 등은 BNT계에서 이러한 거 대 전계유기 변형특성을 나타내는 원인은 완화형 강유


그림 1. Evolution of lead-free piezoelectric research output in terms of (a) publications and (b) patents. 


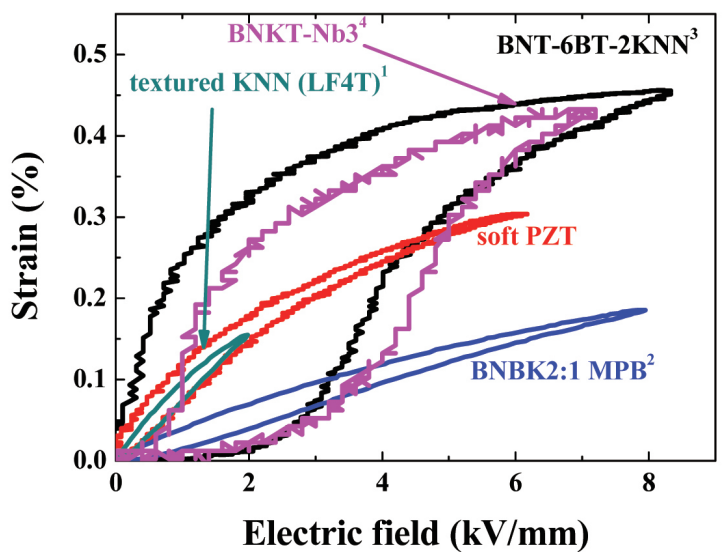

그림 2. Unipolar strain as function of electric field for lead-free piezoceramics. ${ }^{13)}$

전체(relaxor)를 기반으로 에르고딕(ergodic) 완화형 강 유전상이 외부 전계에 의해 강유전상으로 가역적 상전 이 때문이며 이를 초기압전성(incipient piezoelectrics) 으로 정의하였다. ${ }^{14,15)}$ 하지만 이러한 BNT계 무연 압전 세라믹스의 뛰어난 전계유기 변형특성에도 불구하고 그 림 2에서 나타나는 바와 같이 거대변형특성을 유도하는 데 요구되는 전계가 높다는 치명적인 문제점을 가지고 있어서 실제 응용소자 적용에는 여전히 도전적인 상황 이다. 이러한 문제를 해결하기 위하여 많은 연구자들이 다각적인 노력을 기울이고 있으며 그 일환으로 최근에 세라믹/세라믹 복합소재기술이 제안되었으며 이를 제조 하여 거대변형특성을 유도하는데 요구되는 전계 저감화 를 성공하였다.

따라서, 본 기고문에서는 세라믹/세라믹 복합소재 기 술을 활용하여 BNT계 무연 압전세라믹스의 작동전계 저감화에 대한 최근 연구 내용을 살펴보고 향후 연구방 향 및 전망에 대하여 기술하고자 한다.

\section{2. 본론}

\section{2-1. 전계유기 변형특성 향상을 위한 완화형 강유전체 (Relaxor)/강유전체 (Ferroelectrics) 세라믹 복합소재 기술}

일반적으로 복합소재는 물리적 또는 화학적으로 다 른 특성을 나타내는 두 가지 또는 그 이상의 물질로 이 루어진 재료를 의미한다. 이러한 복합재료는 제조한 후 에 각각의 구성 물질은 완성된 복합재료 내에서 구별 이 가능하여야 하며, 이러한 특징으로 혼합물(mixture) 또는 고용체(solid solution)와 구분된다. ${ }^{16)}$ 전통 또 는 구조세라믹스 분야의 경우 세라믹스 기반의 복합소 재를 제조하는 가장 커다란 목적은 균열 전파를 효과 적으로 저지하여 파괴인성(fracture toughness)과 강 도 등의 역학적 성질을 증진시키기 위하여 활용되고 있 으며, ${ }^{17,18)}$ 전자세라믹스 분야의 경우 대부분 높은 취성 (brittleness)을 가지는 세라믹스에 폴리머(polymer) 를 활용하여 유연성(Flexibility)을 보완한 에너지 하베 스터(energy harvester)나 소형 센서로 활용되고 있 다. 전기적 특성 향상을 위한 세라믹스 기반 복합소재 의 경우 상대적으로 많이 알려져 있지 않으나, 1980년 Shrout 교수 팀은 반복적인 고전계인가시 소자의 신뢰 성을 향상 시키기 위하여, 연성(soft) PZT와 반강유전 체(antiferroelectrics)로 구성된 복합소재를 제조하였 다. ${ }^{19)}$ 그 후 1996년에 이르러 Dausch 등은 반강유전체 기질에 강유전상이 존재하게 되면 반강유전-강유전 상 전이에 요구되는 전계를 감소할 수 있다는 것을 발견하 였으며, two-serially-connected capacitor 모델을 적 용하여 감소되는 전계를 첨가되는 강유전상의 양 변화 에 따라 정량화 하는데 성공하였다. ${ }^{20,21)}$ 그 밖에도 세라 믹/세라믹 복합소재는 유전체 소재의 온도안정성, ${ }^{22)}$ 압 전/초전 특성, ${ }^{23,24)}$ 반복적으로 인가되는 고전계에 대한 신뢰성, ${ }^{19)}$ 유전체 tunability ${ }^{25,26)}$ 등에 활용된 사례들이 있으나 압전 세라믹스의 전기기계 변형특성과 관련된 세라믹/세라믹 복합소재 기술은 비교적 최근에 보고되 고 있다.

\section{•0-3형세라믹/세라믹 복합소재}

비스무스계 무연 압전세라믹스에서 PZT에 버금가는 뛰어난 전계유기 변형특성이 보고되었으며, 이러한 거 대 변형특성을 유기하는데 요구되는 전계를 효과적으 로 감소시키는데 0-3 형의 세라믹 복합소재가 제안되 


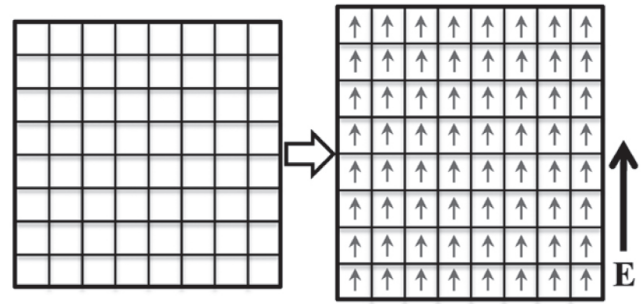

Initial state
Under field

(a) Non-polar-to-ferroelectric phase transition

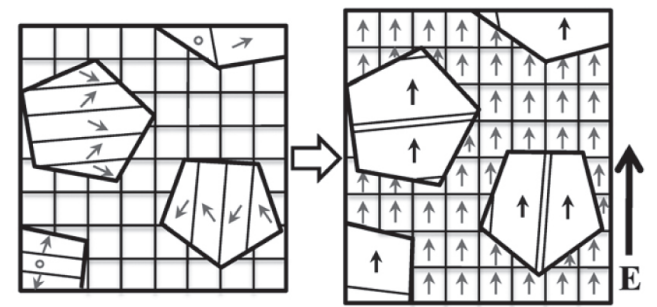

Initial state

Under field

(b) Non-polar-to-ferroelectric phase transition

+ Ferroelectric domain reorientation

그림 3. Schematics of the polarization processes in (a) polycrystalline materials showing electric field-induced phase transition and (b) polycrystalline materials consisting of ferroelectric large grains and relaxor small grains showing electric fieldinduced phase transition. ${ }^{27}$
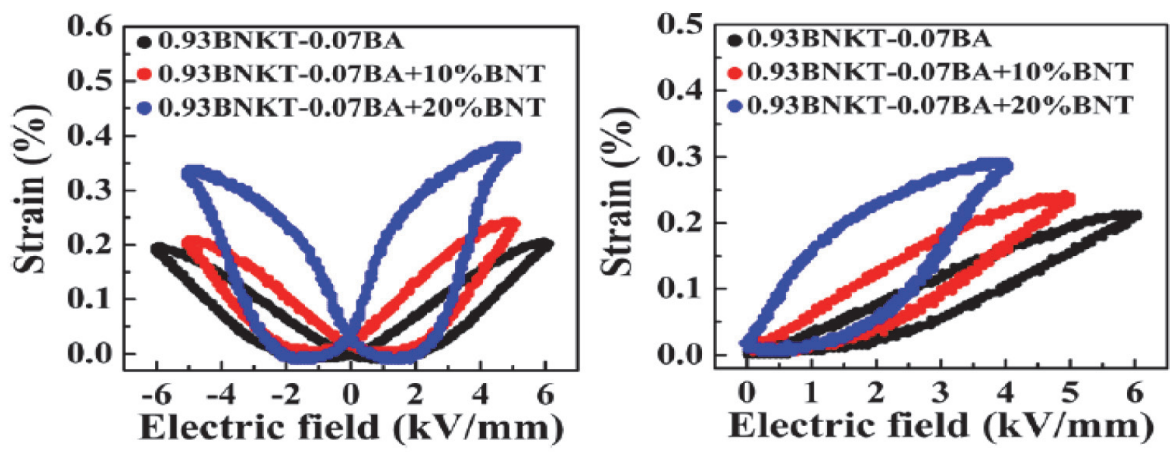

그림 4. Strains versus electric field for 0.93BNKT-0.07BA with and without BNT.27)

었다. 이러한 복합소재는 지난 2011년에 처음보고 되었 으며, ${ }^{27)}$ 일반적인 고상반응법으로 합성한 완화형 강유전 상 $\mathrm{Bi}_{0.5}\left(\mathrm{Na}_{0.75} \mathrm{~K}_{0.25}\right)_{0.5} \mathrm{TiO}_{3}-\mathrm{BiAlO}_{3}(\mathrm{BNKT}-\mathrm{BA})$ 세라믹 스를 모재(matrix)로 활용하고 염용융법으로 합성하여 비교적 큰 입자크기를 가지는 강유전상 $\mathrm{Bi}_{0.5} \mathrm{Na}_{0.5} \mathrm{TiO}_{3}$ (BNT) 세라믹스를 보강재(reinforcement materials)로 첨가하여 제작하였다. 그림 3에 단일 완화형 강유전상과 완화형 강유전상/강유전상 세라믹 복합소재를 도식화하 여 전기장 인가 전 · 후를 비교하여 나타내었다. 일반적 으로 완화형 강유전체의 경우 외부 전기장 인가에 의하 여 강유전상으로 상전이가 유도되고, 완화형 강유전상/ 강유전상 세라믹 복합소재의 경우 첨가된 강유전상은 외부 전계 방향을 따라 강유전 분역의 재배향과 강유전 상의 상전이 현상이 동시에 발생되게 된다.

이러한 복합소재로부터 그림 4 에 나타낸 바와 같 이 완화형 강유전상/강유전상 세라믹 복합소재인
$\mathrm{BNKT}-\mathrm{BA} / \mathrm{BNT}$ 세라믹스가 단일 완화형 강유전상인 0.93BNKT-0.07BA 세라믹스보다 낮은 전계에서 상전 이가 유도되어 향상된 변형특성을 얻었으며, 기존 단일 세라믹스에서 요구되던 $6 \mathrm{kV} / \mathrm{mm}$ 이상의 전계를 $4 \mathrm{kV}$ / $\mathrm{mm}$ 까지 성공적으로 감소시켰다. ${ }^{27}$

그리고 $0.82\left(\mathrm{Bi}_{1 / 2} \mathrm{Na}_{1 / 2}\right) \mathrm{TiO}_{3}-0.18\left(\mathrm{Bi}_{1 / 2} \mathrm{~K}_{1 / 2}\right) \mathrm{TiO}_{3}$ (BNKT) 다결정 세라믹스를 소결한 후 분쇄하여 약 $45-53 \mu \mathrm{m}$ 의 크기로 선별한 강유전상을 모재인 완 화형 강유전상 $\mathrm{Bi}_{0.5}\left(\mathrm{Na}_{0.385} \mathrm{~K}_{0.09} \mathrm{Li}_{0.025}\right)\left(\mathrm{Ti}_{0.975} \mathrm{Ta}_{0.025}\right) \mathrm{O}_{3}$ (BNKLTT) 세라믹스에 첨가하여 제작한 복합소재도 보 고되었으며, 제작된 복합소재는 그림 5 와 같이 저전계 특성 향상에 효과적임을 지난 2015년에 보고되었다. ${ }^{28)}$

또한 최근 2019년에 보고된 연구결과 ${ }^{29)}$ 의 경 우 염용융법으로 합성한 판상 형태의 강유전체 $\mathrm{Bi}_{1 / 2}\left(\mathrm{Na}_{0.78} \mathrm{~K}_{0.22}\right)_{1 / 2} \mathrm{TiO}_{3}(\mathrm{BNKT})$ 입자를 완화형 강유전 체 $0.72\left(\mathrm{Bi}_{1 / 2} \mathrm{Na}_{1 / 2}\right) \mathrm{TiO}_{3}-0.28 \mathrm{SrTiO}_{3}(\mathrm{BNT}-28 \mathrm{ST})$ 


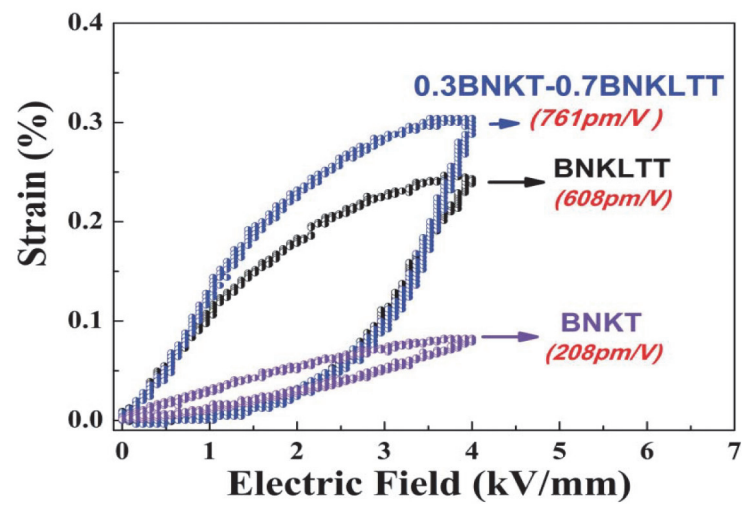

그림 5. Comparison of the unipolar strain properties between the $30 \%$ seed content, BNKLTT matrix and BNKT seed materials. $^{28)}$

에 첨가하여 복합소재를 제작하였으며, 이 복합소재의 미세구조를 그림 6에 나타내었다. 판상 형태의 BNKT 를 첨가하면 큰 $\mathrm{BNKT}$ 입자 주위를 작은 입자크기의 $\mathrm{BNT}-28 \mathrm{ST}$ 세라믹스가 둘러싼 형태의 미세구조가 관찰 된다.

이렇게 제작된 복합소재는 그림 7과 같이 첨가한 판상 의 BNKT에 의하여 완화형 강유전체와 강유전체 사이의 입계에서 두 물질의 변형률 차이가 발생되고 이로인하 여 내부 스트레스가 발생된다. 결론적으로 내부에 발생 된 스트레스로 인하여 전계유기 변형특성을 유도 시키 는데 요구되는 전계가 약 $1.8 \mathrm{kV} / \mathrm{mm}$ (BNT-28ST 세 라믹스의 약 $2.95 \mathrm{kV} / \mathrm{mm}$ 기준)까지 감소 된다고 보고 하였다. 본 기고문에서 소개한 세라믹/세라믹 복합소재 의 변형률 기구에 대한 원리는 다른 형태의 세라믹 복합
소재를 소개한 다음 상세하게 기술 하겠다.

\section{- 하소분말을 이용한 세라믹/세라믹(3-0형) 복합소재}

본 장에서는 현재 보고되고 있는 하소분말을 이용한 세라믹/세라믹 복합소재에 관한 대표적인 연구들을 소 개하고자 한다. 이러한 형태의 복합소재는 합성한 두 종 의 다른 세라믹스를 분말 상태로 혼합 및 소결하여 제 조된다. 이러한 접근은 지난 2014년 독일 Technische Universität Darmstadt 에서 완화형 강유전체 물질과 강유전체 물질로 $0.92\left(\mathrm{Bi}_{1 / 2} \mathrm{Na}_{1 / 2}\right) \mathrm{TiO}_{3}-0.06 \mathrm{BaTiO}_{3}-$ $0.02\left(\mathrm{~K}_{0.5} \mathrm{Na}_{0.5}\right) \mathrm{NbO}_{3}(0.92 \mathrm{BNT}-0.06 \mathrm{BT}-0.02 \mathrm{KNN})$ 세라믹스와 $0.93\left(\mathrm{Bi}_{1 / 2} \mathrm{Na}_{1 / 2}\right) \mathrm{TiO}_{3}-0.07 \mathrm{BaTiO}_{3}$ (0.93BNT-0.07BT) 세라믹스를 각각 선정하여 복합소 재를 성공적으로 제조하여 보고하였다. ${ }^{30)}$ 이 복합소재 의 변형률 특성을 그림 8에 비교하였다. 그 결과 부피비 $10 \%$ 의 강유전체 $0.93 \mathrm{BNT}-0.07 \mathrm{BT}$ 세라믹스를 첨가한 복합소재에서 전계유기 상전이 전계가 감소되어 단일 $0.92 \mathrm{BNT}-0.06 \mathrm{BT}-0.02 \mathrm{KNN}$ 세라믹스 보다 저전계 변형특성이 향상되는 것을 확인할 수 있다.

그 후 2016년과 2017년에 $0.98 \mathrm{Bi}_{1 / 2}\left(\mathrm{Na}_{0.78} \mathrm{~K}_{0.22}\right)_{1 / 2}$ $\mathrm{TiO}_{3}-0.02 \mathrm{LaFeO}_{3}(\mathrm{BNKT} 22 \mathrm{LF})$ 완화형 강유전체 세 라믹스를 모재로 $\mathrm{Bi}_{0.5} \mathrm{Na}_{0.41} \mathrm{~K}_{0.09} \mathrm{Ti}_{0.985} \mathrm{Sn}_{0.015} \mathrm{O}_{3}$ (BNKTSn) 세라믹스와 $0.995 \mathrm{Bi}_{1 / 2}\left(\mathrm{Na}_{0.82} \mathrm{~K}_{0.18}\right)_{1 / 2} \mathrm{TiO}_{3}-$ $0.005 \mathrm{BaZrO}_{3}(\mathrm{BNKT1} 18 \mathrm{BZ})$ 세라믹스를 각각 강유전체 로 혼합한 완화형 강유전체/강유전체 세라믹 복합소재 에 대한 연구가 보고되었다. ${ }^{31,32)}$ 더욱이 강유전체 혼합
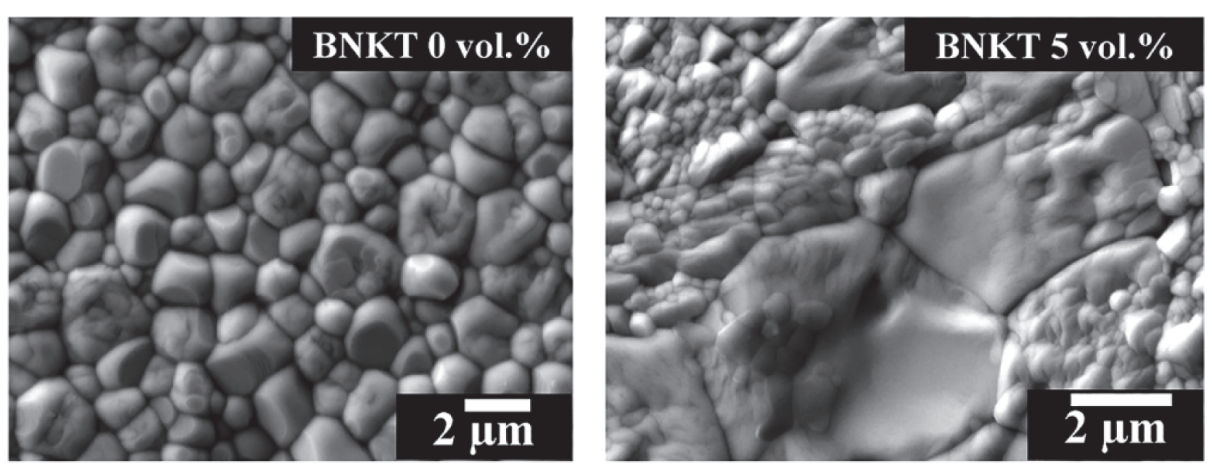

그림 6. FE-SEM images of BNT-28ST/BNKT (0 and 5 vol.\%) composites. The small size BNT-28ST relaxor particles are surrounding the large size ferroelectric particles. ${ }^{29)}$ 
(a)



(b)

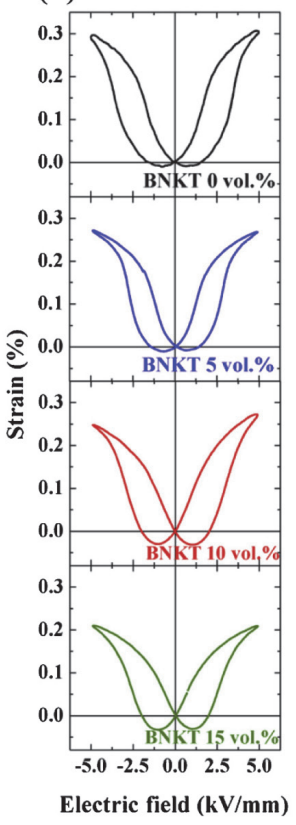

(c)

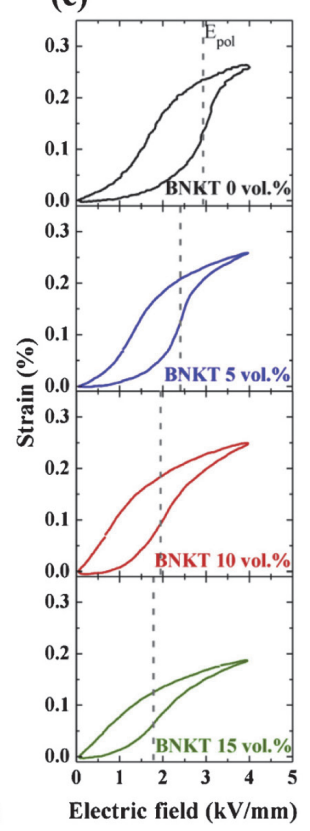

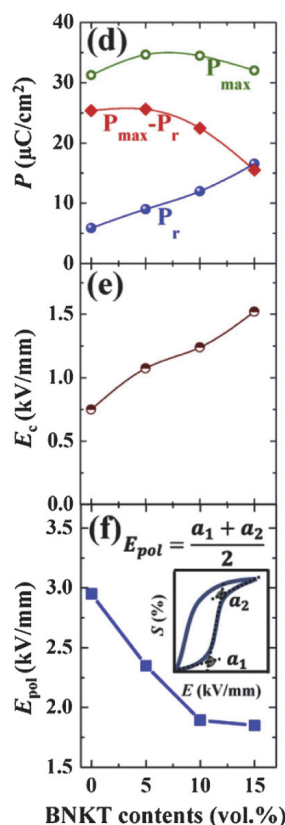

그림 7. (a) Polarization, (b) bipolar, and (c) unipolar strain hysteresis loops of BNT-28ST/BNKT composites (0 to 15 vol.\%.), Extracted values of (d) polarization $\left(P_{\max }, P_{\mathrm{r}}\right.$, and $\left.P_{\max }-P_{\mathrm{r}}\right)$, (e) coercive field $\left(E_{\mathrm{c}}\right)$, and (f) poling field $\left(E_{\mathrm{po}}\right)$ with respect to plat-type BNKT content in vol.\%. The bipolar and unipolar strain hysteresis loops were measured at the frequency of 0.2 $\mathrm{Hz}$ at room temperature. Schematic for the poling field $\left(E_{\mathrm{pol}}\right)$ is in the inset of Fig. $4(\mathrm{f})$. The poling field $\left(E_{\mathrm{pol}}\right)$ is marked with black dashed line in all composited BNT - 28ST/BNKT samples according to the schematic figure. ${ }^{20)}$
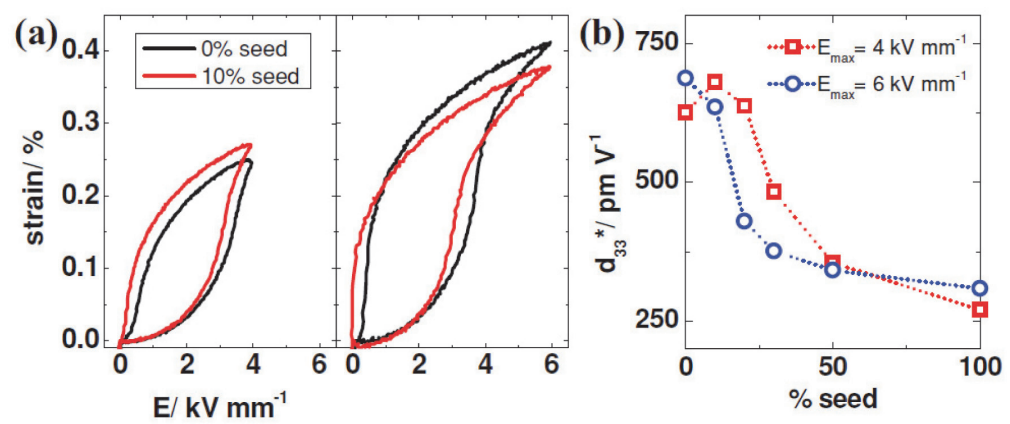

그림 8. (a) Comparison between unipolar strain hystereses of $0 \%$ - and 10\%-seed compositions at two different electric field levels, namely 4 and $6 \mathrm{kV} / \mathrm{mm}$. (b) Changes in $d_{33}{ }^{*}$ (i.e., $S_{\max } / E_{\max }$ ) as a function of seed content. ${ }^{30}$

량 증가와 인가 전계 변화에 따라 가역적(reversible)과 비가역적(irreversible) 상전이거동을 정량화 하였고, 이 를 통하여 혼합한 강유전체가 전계인가 유기 상전이에 요구되는 전계를 효과적으로 낮출 수 있다는 것을 입증 하였다. ${ }^{32)}$ 그 결과 $5 \mathrm{kV} / \mathrm{mm}$ 의 인가전계를 기준으로 완 화형 강유전체인 단일 BNKT22LF 세라믹스의 경우 약 $636 \mathrm{pm} / \mathrm{V}$ 의 정규변형특성 $\left(S_{\max } / E_{\max }\right.$ 또는 $\left.d_{33}{ }^{*}\right)$ 을 가
지는 것에 비하여 부피비로 $30 \%$ 의 강유전체가 혼합된 완화형 강유전체/강유전체 세라믹 복합소재의 $d_{33}{ }^{*}$ 의 경 우 $4 \mathrm{kV} / \mathrm{mm}$ 의 인가전계에서 $690 \mathrm{pm} / \mathrm{V}$ 값을 얻어 작 동전계의 저감화 및 변형특성 향상을 성공시켰다. ${ }^{32)}$

\section{2-2. 완화형 강유전체/강유전체 세라믹 복합소재의 변형기구}


(a)

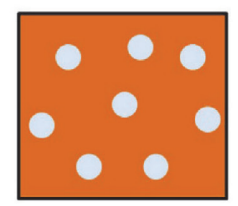

0-3 ferroelectric/relaxor composite



2-2 ferroelectric/relaxor composite (b)
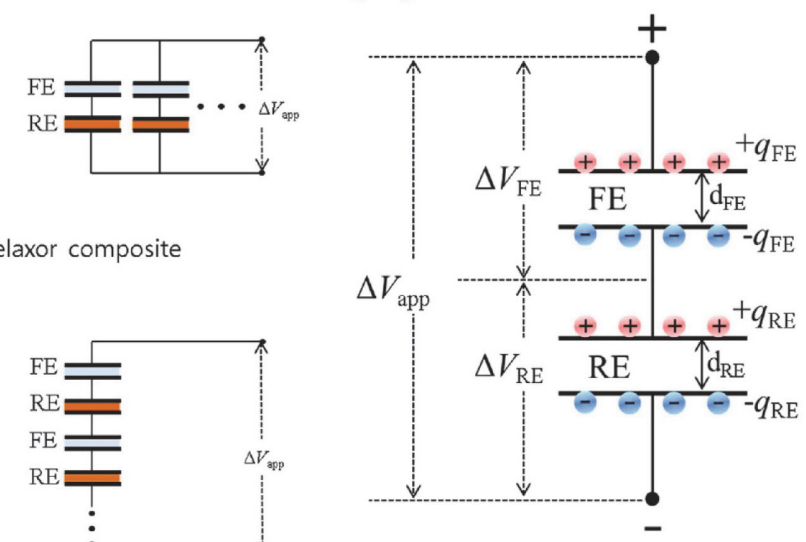

그림 9. (a) Schematic illustration of 0-3 and 2-2 type ferroelectric/relaxor composite with an equivalent circuit for each type and (b) an explanation for the expected outcomes due to the formation of composites based on the polarization-coupling mechanism. ${ }^{33)}$

지금까지 비스무스계 무연 압전세라믹스의 전계유기 변형특성 향상 및 작동전계 저감화에 대한 다양한 형태 의 세라믹/세라믹 복합소재에 대하여 살펴보았다. 본 장 에서는 이러한 복합소재 제조를 통하여 개선된 전계유 기 변형특성에 대한 원리를 소개하고자 한다.

그림 9 (a)와 같이 0-3 또는 2-2 형 강유전체/완화형 강유전체 세라믹 복합소재는 직렬로 연결된 두개의 커 패시터로 묘사되며 이를 통하여 각 물질의 분극이 결합 되어 있는 것으로 표현할 수 있다. ${ }^{30)}$ 한국전기연구원의 연구결과를 따르면 서로 다른 유전율을 가지는 두 개 상 의 공존으로 인하여 완화형 강유전체의 전계유기 상전 이의 시작을 촉진할 수 있는 불균일한 로컬 전기장(local field)이 발생되게 된다. ${ }^{27)}$ 이러한 이유는 그림 9 (b)에 나타낸 바와 같이 완화형 강유전체와 강유전체가 분극 결합(polarization coupling)으로 인하여 실제로 각 물 질에 인가되는 전계는 외부에서 인가한 전계와 다를 수 있기 때문이다. 하지만 이 메커니즘의 경우 강유전상이 일반적으로 자신의 항전계 보다 높은 전계에서 완화형 강유전상보다 높은 분극값을 가져야 비로소 분극 결합 의 효과를 기대할 수 있으며 이를 통하여 완화형 강유전 체의 거대 변형특성을 유도시킬 수 있는 전계를 충분하 게 낮출 수 있다. ${ }^{27,30)}$
한편, Zhang 등은 지난 2015년 2-2형의 강유전체/ 완화형 강유전체 세라믹 복합소재에서 전기장 인가에 따른 변형률 차이로 인하여 복합소재 내부의 전기적 반 응 및 잔류 응력의 변화가 발생이 되고 이로 인하여 전 계유기 상전이 전계가 감소되는 변형률 결합(strain coupling) 기구를 제안하였다. ${ }^{34)}$ 그 후 2019년에 0-3 형 복합소재를 활용하여 변형률 기반 기구를 성공적으 로 입증한 결과가 보고되었다. ${ }^{29)}$ 변형률 결합 기구에 대 하여 조금 더 상세하게 살펴보면 그림 10에 나타낸 바 와 같이 외부에서 전계를 인가하기 전, 즉 초기 상태에 완화형 강유전체 분역이 상대적으로 큰 크기의 강유전 체 분역을 둘러싸고 있는 구조를 가지며, 이 때는 모든 강유전체 및 완화형 강유전체 분역들이 무작위 방향으 로 배향되어 있다. 하지만 강유전체 분역 부분에 분극전 계(polarization field; $E_{\mathrm{pol}}$ ) 이상의 전계가 인가되면 주 위의 완화형 강유전체에 응력을 가하게 된다. 이때, 인 가한 전계가 강유전체 분역을 전계방향으로 배향하기에 충분한 강도에 도달하게 되면 강유전체 분역의 빠른 배 향성으로 인하여 강유전체 주변에 응력이 발생되는데, 이로 인하여 완화형 강유전체는 전계인가 방향으로 신 장(elongation) 응력을 그리고 전계인가 방향으로 압축 (compressive) 응력을 받게 된다. 그 결과 복합소재 모 


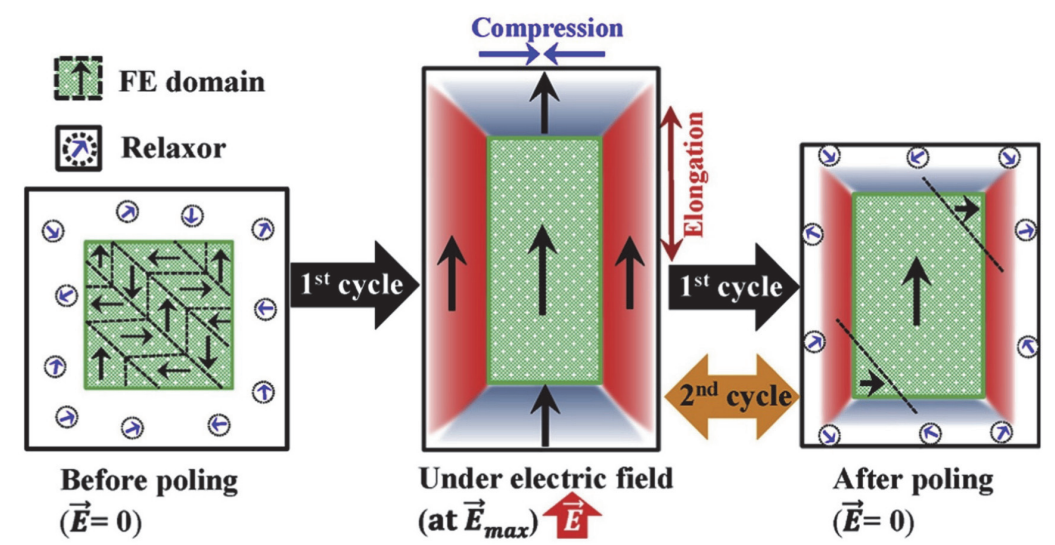

그림 10. Schematic of strain coupling mechanism. ${ }^{29}$

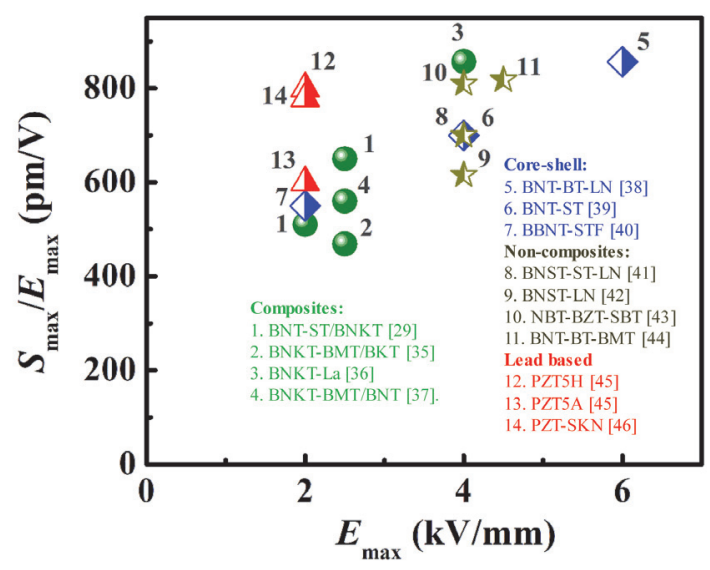

그림 11. Comparison of normalized strain between PZT and BNT-based materials. ${ }^{29}$

재인 완화형 강유전체에서 단일 소재 보다 상대적으로 낮은 작동전계에도 큰 변형특성을 얻을 수 있게 된다. 또한 외부인가 전계가 다시 “0”으로 감소되었을 때, 복 합소재는 생성되어 있던 인장 응력으로 인하여 완전히 초기 상태 (분극 전)로는 복원되지 않는다. 다시 말해서 일부 완화형 강유전체 분역은 초기 상태로 복원되나 강 유전체 분역에 의해 내부 응력이 인가되고 있는 부분의 분역은 잔재하게 됨으로 다음 전계인가부터 상대적으로 낮은 전계에서도 완화형 강유전체의 상전이가 유도된다 는 원리이다.

\section{3. 결론}

현재까지 PZT계 압전 세라믹스를 대체하기 위하여 전 세계적으로 무연 압전세라믹스에 대한 연구가 활발 하게 진행되고 있으나 성능적인 측면에서 다재다능한 PZT계 압전 세라믹스에 미치지 못하고 있는 실정이다. 최근 보고된 비스무스계 무연 압전세라믹스에서 PZT에 버금가는 전계유기 변형특성이 보고되고는 있으나 요 구되는 높은 작동전계가 문제되고 있다. 따라서, 본 기 고문에서는 이러한 문제를 해결하기 위하여 비스무스 계 무연 압전세라믹스와 관련된 최근에 제안되고 있는 세라믹/세라믹 복합소재 기술과 그 효과에 대하여 소개 하였다. 사실 코어쉘(core-shell) 구조 또는 소재 합성 시 자연적으로 강유전성과 완화형 강유전성이 공존하 는 구조를 통하여서도 작동전계를 효과적으로 감소시킬 수 있다고 보고되고 있지만 본 기고문에서는 복합소재 에 관한 내용을 중점적으로 다루고 있기 때문에 제외하 였다. 비스무스계 무연 압전세라믹스의 세라믹/세라믹 복합소재는 완화형 강유전체 세라믹스를 모재로 강유 전체 상을 보강제로 첨가하여 제작되고 첨가한 강유전 체로 인하여 모재인 완화형 강유전체의 전계유기 상전 이 전계의 크기를 감소시킬 수 있으며, 그 원리는 두 가 지의 다른 물질이 가지는 유전율 차이에 의한 분극 결합 (polarization coupling model) 또는 내부응력에 기인 
된 변형률 결합(strain coupling model)으로 제안되었 다. 이러한 연구내용들을 바탕으로 얻어진 결과를 그림 11에 요약하였으며 제안되고 있는 복합소재기술이 비스 무스계 무연 압전세라믹스의 작동전계를 효과적으로 감 소시키는 것을 확인하였다. 이러한 결과들은 비록 연성 $\mathrm{PZT}$ 계 세라믹스에 비하여 정규변형특성 $\left(S_{\max } / E_{\max }\right)$ 은 여전히 개선되어야 할 여지를 내포하고 있지만 향후 실 용화에 대한 가능성을 높여주고 있는 것으로 판단된다. 멀지 않은 미래에 무연 압전세라믹스가 실용화에 성공 할 수 있을 것이라는 희망을 품고 본 기고문의 끝을 맺 는다.

\section{감사의 글}

이 논문은 정부(교육부, 과학기술정보통신부)의 재원 으로 한국연구재단의 지원을 받아 수행된 연구임(No. 2016R1D1A3B01008169, No. 2019R1H1A1079869).

\section{REFERENCES}

1. B. Jaffe, W. R. Cook, and H. Jaffe, "Piezoelectric Ceramics," Academic Press, 1971.

2. K. Uchino, "Piezoelectric Actuators and Ultrasonic Motors," Kluwer Academic Publishers, Boston, 1997.

3. A. J. Bell and O. Deubzer. "Lead-Free Piezoelectrics-The Environmental and Regulatory Issues," MRS Bulletin, 43, 581-7 (2018)

4. J. Rödel, J. F. Li, "Lead-Free Piezoceramics: Status and Perspectives," MRS Bulletin, 43, $576-80$ (2018)

5. Quoted from the invited talk by professor Takenaka at the ISAF, Santa Fe, USA (2008).

6. W. Jo, "Lead-Free Incipient Piezoceramics for Actuator Applications (in Korean)," Physics and High Technology, 22, 8-13 (2013).

7. T. Takenaka, K. I. Maruyama and K. Sakata, " $\left(\mathrm{Bi}_{1 / 2} \mathrm{Na}_{1 / 2}\right) \mathrm{TiO}_{3}-\mathrm{BaTiO}_{3}$ System for Lead-Free Piezoelectric Ceramics," Jpn. J. Appl.. Phys., 30, 2236 (1991).

8. A. Sasaki, T. Chiba, Y. Mamiya and E. Otsuki,
"Dielectric and Piezoelectric Properties of $\left(\mathrm{Bi}_{0.5} \mathrm{Na}_{0.5}\right) \mathrm{TiO}_{3}-\left(\mathrm{Bi}_{0.5} \mathrm{~K}_{0.5}\right) \mathrm{TiO}_{3}$ Systems," Jpn. J. Appl. Phys., Part 1, 38, 5564 (1999).

9. Y. Saito, H. Takao, T. Tani, T. Nonoyama, K. Takatori, T. Homma, T. Nagaya and M. Nakamura, "Lead-Free Piezoceramics," Nature, 432, 84 (2004).

10. M. H. Lee, D. J. Kim, J. S. Park, S. W. Kim, T. K. Song, M. - H. Kim, W. - J. Kim, D. Do, I. - K. Jeong," High-Performance Lead-Free Piezoceramics with High Curie Temperatures," Adv. Mater., 27, 6976-82 (2015).

11. W. Liu and X. Ren, "Large Piezoelectric Effect in Pb-Free Ceramics," Phys. Rev. Lett., 103, 257602 (2009).

12. S. T. Zhang, A. B. Kounga, E. Aulbach, H. Ehrenberg and J. Rödel, "Giant Strain in Lead-Free Piezoceramics $\mathrm{Bi}_{0.5} \mathrm{Na}_{0.5} \mathrm{TiO}_{3}$ $\mathrm{BaTiO}_{3}-\mathrm{K}_{0.5} \mathrm{Na}_{0.5} \mathrm{NbO}_{3}$ System," Appl. Phys. Lett., 91, 112906 (2007).

13. J. Rödel, W. Jo, K. T. P. Seifert, E. M. Anton, T. Granzow, "Perspective on the Development of Lead-Free Piezoceramics," J. Am. Ceram. Soc., 92, $1153-1177$ (2009).

14. W. Jo, R. Dittmer, M. Acosta, J. Zang, C. Groh, E. Sapper, K. Wang and J. Rödel, "Giant Electric-Field - Induced Strains in Lead-Free Ceramics For Actuator Applications - Status and Perspective," J. Electroceram., 29, 71 (2012).

15. H. S. Han, W. Jo, J. K. Kang, C. W. Ahn, I. W. Kim, K. K. Ahn, J. S. Lee, "Incipient Piezoelectrics and Electrostriction Behavior in $\mathrm{Sn}$ - doped $\mathrm{Bi}_{1 / 2}\left(\mathrm{Na}_{0.82} \mathrm{~K}_{0.18}\right)_{1 / 2} \mathrm{TiO}_{3}$ Lead-free Ceramics," J. Appl. Phys., 113, 154102 (2013).

16. M. Fazeli, J. P. Florez, R. A. Simão (April 2019). "Improvement in Adhesion of Cellulose Fibers to the Thermoplastic Starch Matrix by Plasma Treatment Modification," Composites Part B, 163, $207-216$ (2019).

17. 김현이, 이동한, “세라믹 복합재료," 세라미스트, 9 , 125 - 31 (1994).

18. 박상환, 김영욱, 이준근, "세라믹 기지 복합재료 제 조 기술," 세라미스트, 5, $145-55$ (1990).

19. T. R. Shrout, W. A. Schulze and J. V. Biggers, "Electromechanical Behavior of 
Antiferroelectric - Ferroelectric Multilayer PZT Based Composites," Ferroelectrics, 29, 129 - 34 (1980).

20. D. E. Dausch, E. Furman, F. Wang and G. H. Haertling, "PLZT - based Multilayer Composite Thin Films, Part I: Experimental Investigation of Composite Film Structures," Ferroelectrics, 177, $221-36$ (1996).

21. D. E. Dausch, E. Furman, F. Wang, G. H. Haertling, "PLZT - based Multilayer Composite Thin Films, Part II: Modeling of the Dielectric and Hysteresis Properties," Ferroelectrics, 177, $237-53$ (1996).

22. O. Furukawa, M. Harata, M. Imai, Y. Yamashita and S. Mukaeda, "Low Firing and High Dielectric Constant X7R Ceramic Dielectric for Multilayer Capacitors based on Relaxor and Barium Titanate Composite," J. Mater. Sci., 26, 5838-42 (1991).

23. H. Komiya, Y. Naito, T. Takenaka, and K. Sakata, "Piezoelectric and Pyroelectric Composite Ceramics of the Multilayer Type by Tape Casting," Jpn. J. Appl. Phys. Part 1, 28, $114-6$ (1989).

24. A. Yoneda, T. Takenaka and K. Sakata, "Composite Piezoelectric Ceramics of $(\mathrm{LiBi})_{1 / 2}-$ Modifed PZT System," Jpn. J. Appl. Phys., Part 1, 28, $95-7$ (1989).

25. V. O. Sherman, A. K. Tagantsev and N. Setter, "Model of a Low-Permittivity and High-Tunability Ferroelectric Based Composite," Appl. Phys. Lett., 90, 162901-3 (2007).

26. V. O. Sherman, A. K. Tagantsev, N. Setter, D. Iddles and T. Price, "Ferroelectric-Dielectric Tunable Composites," J. Appl. Phys., 99, 074104-10 (2006)

27. D. S. Lee, D. H. Lim, M. S. Kim, K. H. Kim, S. J. Jeong, "Electric Field-Induced Deformation Behavior in Mixed $\mathrm{Bi}_{0.5} \mathrm{Na}_{0.5} \mathrm{TiO}_{3}$ and $\mathrm{Bi}_{0.5}\left(\mathrm{Na}_{0.75} \mathrm{~K}_{0.25}\right)_{0.5} \mathrm{TiO}_{3}-\mathrm{BiAlO}_{3}$, Appl. Phys. Lett., 99, 062906-3 (2011).

28. T. H. Dinh, C. H. Yoon, J. K. Kang, Y. H. Hong, J. S. Lee, "Enhanced Low - Field Strain in Bi-Based Lead-Free Ferroelectric-Relaxor Composites," Ferroelectrics, 487, $142-8$
(2015).

29. M. Sheeraz, A. Khaliq, A. Ullah, H. S. Han, A. Khan. A. Ullah, I. W. Kim, T. H. Kim and C. W. Ahn, "Stress Driven High Electrostrain at Low Field in Incipient Piezoelectrics," $J$. Eur. Ceram. Soc., 39, 4688-96 (2019).

30. C. Groh, D. J. Franzbach, W. Jo, K. G. Webber, J. Kling, L. A. Schmitt, H. J. Kleebe, S. J. Jeong, J. S. Lee and J. Rödel, "Relaxor/ Ferroelectric Composites: A Solution in the Quest for Practically Viable Lead-Free Incipient Piezoceramics," Adv. Funct. Mater., 24, $356-62$ (2014).

31. T. H. Dinh, J. K. Kang, H. T. K. Nguyen, T. A. Duong, J. S. Lee, "Giant Strain in LeadFree Relaxor/Ferroelectric Piezocomposite Ceramics,” J. Korean Phys. Soc., 68, 1439-44 (2016).

32. T. H. Dinh, V. D. N. Tran, T. T. Nguyen, Q. T. N. Hoang, H. S. Han, J. S. Lee, "The Reduced Reversible Phase Transition Field of Lead - Free Bi-Based Ceramic Composites by Adding Nonergodic Relaxor," Ceram. Int., 43, 17160 - 6 (2017).

33. C. W. Ahn, C. H. Hong, B. Y. Choi, H. P. Kim, H. S. Han, Y. Hwang, W. Jo, K. Wang, J. F. Li, I. W. Kim, "A Brief Review on Relaxor Ferroelectrics and Selected Issues in Lead-Free Relaxors," J. Korean Phys. Soc., 68, 1481-94 (2016).

34. H. Zhang, C. Groh, Q. Zhang, W. Jo, K.G. Webber and J. Rödel, "Large Strain in Relaxor/Ferroelectric Composite Lead - Free Piezoceramics," Adv. Electron. Mater., 1, 1500018 (2015).

35. A. Khaliq, M. Sheeraz, A. Ullah, H.J. Seog, C.W. Ahn, T.H. Kim, S. Cho, I.W. Kim, "Ferroelectric Seeds - Induced Phase Evolution and Large Electrostrain Under Reduced Poling Field in Bismuth-Based Composites," Ceram. Int., 44, $13278-13285$ (2018).

36. T. H. Dinh, J. K. Kang, J. S. Lee, N. H. Khansur, J. Daniels, H. Y. Lee, F. Z. Yao, K. Wang, J. F. Li, H. S. Han, W. Jo, "Nanoscale Ferroelectric/Relaxor Composites: Origin of Large Strain in Lead - Free Bi - Based Incipient 
Piezoelectric Ceramics," J. Eur. Ceram. Soc., 36, 3401-3407 (2016).

37. A. Khaliq, M. Sheeraz, A. Ullah, J. S. Lee, C. W. Ahn, I. W. Kim, "Large Strain in $\mathrm{Bi}_{0.5}\left(\mathrm{Na}_{0.78} \mathrm{~K}_{0.22}\right) 0.5 \mathrm{TiO}_{3}-\mathrm{Bi}\left(\mathrm{Mg}_{0.5} \mathrm{Ti}_{0.5}\right) \mathrm{O}_{3}$ Based Composite Ceramics Under Low Driving Field," Sens. Actuators A Phys., 258, 174-181 (2017).

38. J. Chen, Y. Wang, Y. Zhang, Y. Yang, R. Jin, "Giant Electric Field - Induced Strain at Room Temperature in $\mathrm{LiNbO}_{3}$ - Doped $0.94\left(\mathrm{Bi}_{0.5} \mathrm{Na}_{0,5}\right)$ $\mathrm{TiO}_{3}-0.06 \mathrm{BaTiO}_{3}$," J. Eur. Ceram. Soc., 37, $2365-2371$ (2017).

39. M. Saleem, L. D. Hwan, I. S. Kim, M. S. Kim, A. Maqbool, U. Nisar, S. A. Pervez, U. Farooq, M. U. Farooq, H. M. W. Khalil, S. J. Jeong, "Revealing of Core Shell Effect on Frequency-Dependent Properties of Bi-Based Relaxor/Ferroelectric Ceramic Composites," Sci. Rep., 8, 14146 (2018).

40. J. H. Cho, J. S. Park, S. W. Kim, Y. H. Jeong, J. S. Yun, W. I. Park, Y. W. Hong, J. H. Paik, "Ferroelectric Properties and Core Shell Domain Structures of $\mathrm{Fe}$-Modified $0.77 \mathrm{Bi}_{0.5} \mathrm{Na}_{0.5} \mathrm{TiO}_{3}-0.23 \mathrm{SrTiO}_{3}$ Ceramics, $J$. Eur. Ceram. Soc., 37, $3313-3318$ (2017).

41. Y. Zhu, Y. Zhang, B. Xie, P. Fan, M. A. Marwat, W. Ma, C. Wang, B. Yang, J. Xiao, H.
Zhang, "Large Electric Field - Induced Strain in $\mathrm{AgNbO}_{3}-$ Modified $0.76 \mathrm{Bi}_{0.5} \mathrm{Na}_{0.5} \mathrm{TiO}_{3}-$ $0.24 \mathrm{SrTiO}_{3}$ Lead - Free Piezoceramics," Ceram. Int., 44, 7851-7857 (2018).

42. Y. H. Hong, H. S. Han, G. H. Jeong, Y. S. Park, T. H. Dinh, C. W. Ahn, J. S. Lee, "High Electromechanical Strain Properties by the Existence of Nonergodicity in $\mathrm{LiNbO}_{3}$ Modified $\mathrm{Bi}_{1 / 2} \mathrm{Na}_{1 / 2} \mathrm{TiO}_{3}-\mathrm{SrTiO}_{3}$ Relaxor Ceramics," Ceram. Int. , 44, $21138-21144$ (2018).

43. X. Liu, S. Xue, F. Li, J. Ma, J. Zhai, B. Shen, F. Wang, X. Zhao, H. Yan, "Giant Electrostrain Accompanying Structural Evolution in LeadFree NBT-Based Piezoceramics," J. Mater. Chem. C, 6, 814-822 (2018).

44. A. Ullah, M. Alam, A. Ullah, C. W. Ahn, J. S. Lee, S. Cho, I. W. Kim, "High Strain Response in Ternary $\mathrm{Bi}_{0.5} \mathrm{Na}_{0,5} \mathrm{TiO}_{3}-\mathrm{BaTiO}_{3}-\mathrm{Bi}\left(\mathrm{Mn}_{0.5} \mathrm{Ti}_{0.5}\right)$ $\mathrm{O}_{3}$ Solid Solutions," RSC Adv. , 6, 63915-63921 (2016).

45. T. R. Shrout, S. J. Zhang, "Lead-Free Piezoelectric Ceramics: Alternatives for PZT?," J. Electroceram., 19, 111-124 (2007).

46. N. J. Donnelly, T. R. Shrout, C. A. Randall, "Addition of a Sr, K, Nb (SKN) Combination to PZT(53/47) for High Strain Applications" J. Am. Ceram. Soc., 90, 490-495 (2007). 


\section{특 집 ㅁㅁ한형수, 즈엉 짱 안, 안창원, 조욱, 이재신}

\section{○○ 한 형 수}

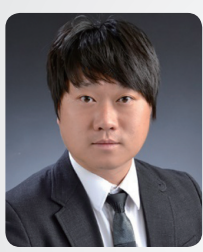

- 2013년 울산대학교 첨단소재공학부 공학박사

- 2013년 울산대학교 첨단소재공학부 박사후연구원

- 2014년 독일 다름슈타트공과대학 재료공학과 박사후연구원

- 2015년 울산과학기술원 신소재공학부 박사후연구원

○ 2016년 울산대학교 첨단소재공학부 연구교수

\section{○○ 안 창 원}

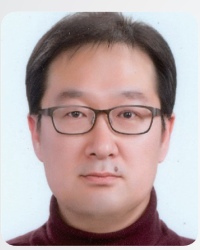

(0) 2007년 울산대학교 물리학과 이학박사

2007년 기초과학지원연구원 박사후연구원

- 2009년 전자부품연구원 박사후연구원

○ 2011년 울산대학교 물리학과 연구교수

\section{๑ ○ 이 재 신}

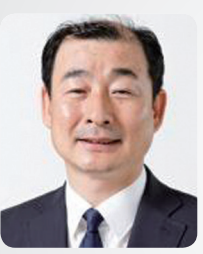

ㅇ 1986년 한국과학기술원 재료공학과 공학박사

- 1986년 한국전자통신연구원 선임연구원

○ 1993년 울산대학교 첨단소재공학부 교수

\section{๑。 즈엉 짱 안}

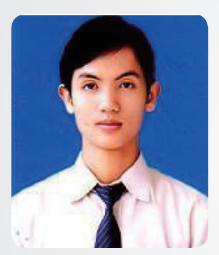

- 2010년 베트남 후에 대학교 물리학과 학사

2 2010년 베트남 후에 대학교 물리학과 강사

( 2015년 울산대학교 첨단소재공학부 석박사 통합과정

\section{으조 욱}

( 2005년 서울대학교 재료공학과 공학박사

- 2005 년 서울대학교 박사후연구원

- 2006년 서울대학교 선임연구원

- 2006년 서울대학교 재료공학과 박사후연구원

( 2007년 독일 다름슈타트공과대학 책임연구교수

○ 2014년 울산과학기술원 신소재공학부 부교수 